\title{
Comparison of the outcome of radiofrequency ablation or hepatic resection between solitary hepatocellular carcinoma and oligonodular hepatocellular carcinoma meeting Milan criteria: a systematic review and meta-analysis
}

\author{
Rajeev Adhikari ${ }^{1}$, Tianfu Wen ${ }^{1}$, Parvani Shrestha $^{2}$, Pooja Adhikari ${ }^{3}$
}

\author{
${ }^{1}$ Department of Liver Surgery and Transplantation Center, West China Hospital, Sichuan Chengdu, China \\ ${ }^{2}$ Department of Acupuncture, Nepal -China Boda Hospital, Nepal \\ ${ }^{3}$ Jingzhou first peoples hospital, Yangtze University, Jingzou, Hubei, China
}

Received: 14 June 2019

Revised: 13 August 2019

Accepted: 14 August 2019

\author{
*Correspondence: \\ Dr. Tianfu Wen, \\ E-mail: tianfu1962@163.com
}

Copyright: ( ) the author(s), publisher and licensee Medip Academy. This is an open-access article distributed under the terms of the Creative Commons Attribution Non-Commercial License, which permits unrestricted non-commercial use, distribution, and reproduction in any medium, provided the original work is properly cited.

\begin{abstract}
There are more literatures on the comparison of the outcome of small HCC between HR and RFA, but rare is about the comparison of the outcome between small solitary HCC and small oligonodular HCC meeting Milan criteria by HR or by RFA. Thus, the aim of the present study is to evaluate the outcome between small solitary HCC and small oligonodular HCC meeting Milan criteria treated by HR or by RFA. Total eighteen studies including 4,823 patients was included in this study. Among them LR group included 2,564 cases, and RFA group included 2,259 cases. We divided them into small solitary HCC sub-group and small oligonodular HCC sub-group and compared the survival difference between them. In the HR group, 1, 3, and 5 years OS of the small solitary HCC sub-group were 93.9\%, $81.3 \%$, and $72.0 \%$, and the small oligonodular HCC sub-group were $83.3 \%, 70.4 \%$, and $45.4 \%$, respectively. For the DFS in the HR group, 1, 3, and 5 years of the small solitary HCC sub-group were $76.4 \%, 56.0 \%$, and $44.0 \%$, and $65.9 \%, 40.7 \%$, and $11.1 \%$ of the small oligonodular HCC sub-group, respectively. In the RFA group, 1, 3, and 5 years OS of the small solitary HCC sub-group were $91.2 \%, 74.1 \%$, and 54.5\%, and the small oligonodular HCC sub-group were $82.0 \%, 55.4 \%$, and $38.2 \%$, respectively. For the DFS in the RFA group, 1, 3, and 5years of the small solitary HCC sub-group were $74.1 \%, 49.8 \%$, and $22.1 \%$, and $62.6 \%$ and $37.3 \%, 8.2 \%$ of the small oligonodular HCC subgroup, respectively.
\end{abstract}

Keywords: Hepatocellular carcinoma, Hepatic resection, Surgery, RFA, Solitary, Oligonodular, Multinodular

\section{INTRODUCTION}

Hepatocellular carcinoma (HCC) is the third leading cause of cancer-related death worldwide. Liver transplantation, hepatic resection and radiofrequency ablation are used to be considered three radical treatments for small HCC (early HCC or Milan criteria). But in recent years, with the experience and data accumulated, literatures show that radiofrequency ablation for small
HCC is little poorer in survival rate compared with HR. ${ }^{1}$ There are more literatures on the comparison of the outcome of small HCC between HR and RFA, but rare is about the comparison of the outcome between small solitary HCC and small oligonodular HCC meeting Milan criteria by HR or by RFA. Thus, the aim of the present study is to evaluate the outcome between small solitary HCC and small oligonodular HCC meeting Milan criteria treated by HR or by RFA. In this systemic review and 
meta-analysis included 4 RCTs to compare HR with RFA for small HCC. ${ }^{2-5}$

\section{METHODS}

\section{Search strategy and study identification}

Electronic databases were searched for studies and literatures in the PubMed Medline, Ovid Medline, Embase and Cochrane library from June 2001 to March 2018. Searching terms were used as hepatocellular or hepatic or liver, and tumor or carcinoma or cancer, and solitary or single and oligonodular or oligonodule or multinodular or multimodule, and Milan criteria, and surgery or resection or ablation, with restriction of English language but not to article type. The titles of the articles were reviewed and a reference check was performed to determine whether the article met the inclusion criteria.

The flow diagram of searching strategy is shown in Figure 1. A total of 672 articles and abstracts were identified by initial searches and 0 manuscripts were further added after manual reference search. After records remove of duplicates 636 articles were by manual screening of the titles, abstracts and animal experiments. A recorded excluded 540 papers were excluded after reading the full text among them we screened 96 papers. 36 full-text articles assessed for eligibility after that we excluded 18 articles with reason (1. Failed to provide sufficient data $(n=7) 2$. Titles and abstract screening $(n=8)$ and 3. Beyond Milan criteria $(n=3))$. Finally, 18 articles were included after reading the full papers. ${ }^{2-19}$
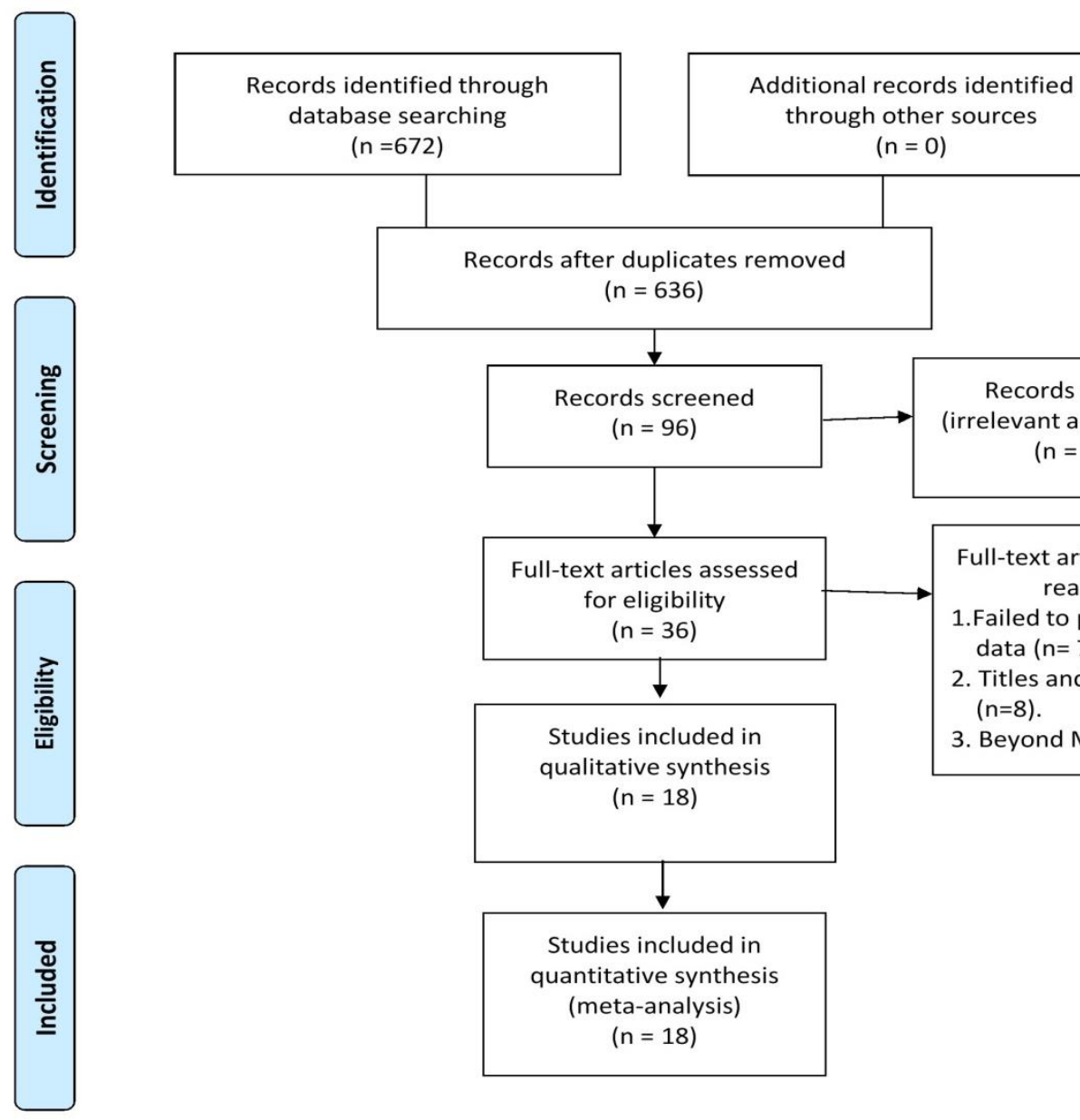

Records after duplicates removed

$(n=636)$

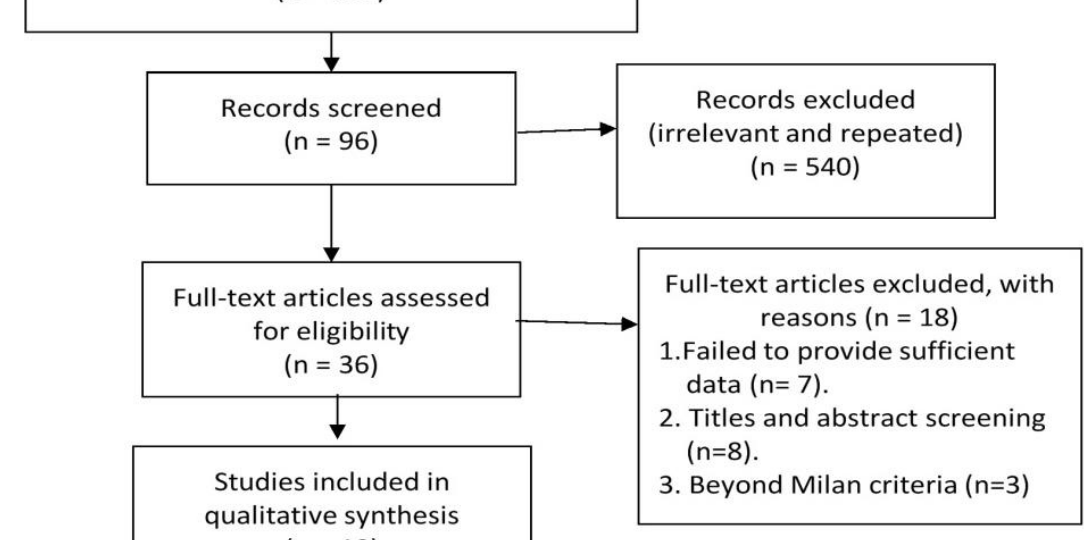

qualitative synthesis

$(n=18)$
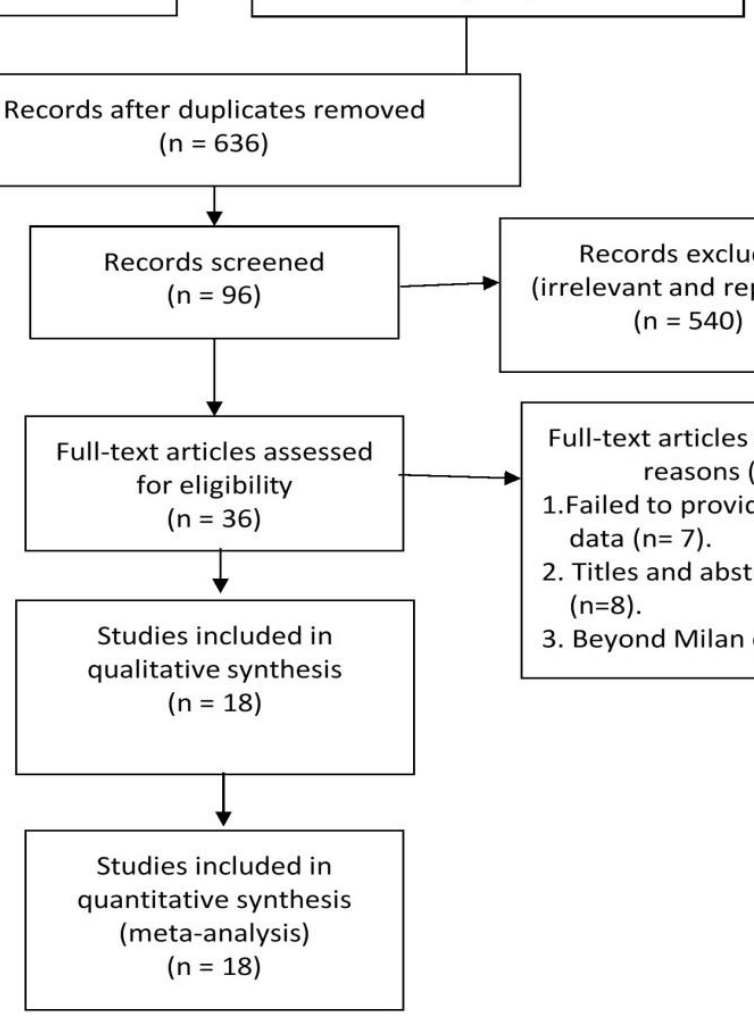

From: Moher D, Liberati A, Tetzlaff J, Altman DG, The PRISMA Group (2009). Preferred Reporting Items for Systematic Reviews and MetaAnalyses: The PRISMA Statement. PLoS Med 6(7): e1000097. doi:10.1371/journal.pmed1000097

For more information, visit www.prisma-statement.org.

Figure 1: Flow diagram of searching strategy. 
Besides, the references of retrieved articles and reviews were manually checked to identify additional articles meeting the inclusion in this meta-analysis for inclusion of potential complements. The language of the paper was restricted to English, however, no restrictions on publication year, geographical location, and the age of the participants. In addition, we augmented the searches with the subject heading terms option as much as possible. A list of titles and abstracts of potentially relevant studies were generated and imported in-to managerial software (EndNote®) X8.2.

\section{Ethical statement}

All results and analyses were based on previous ethically approved studies thus no further ethical approval and patient consent is required for this meta-analysis.

\section{Inclusion and exclusion criteria}

Included studies should meet the following criteria such as studies should be published in English language irrespective of research methods, manuscripts containing data of comparison of HR or RFA between small solitary tumor and small oligonodular tumor, and manuscripts should contain major outcome determinants of long-term survival such as patient demographics, operative detail, tumor characteristics (tumor number and diameter), median survival rate, yearly survival rates, and/or effect estimates (OR) assessing the association of tumor size with its corresponding $95 \% \mathrm{CI}$.

Studies that were conducted on animals and with insufficient data were all excluded. When two studies were reported including same patients totally or partly by the same institution, the publication with more sample size was included. Studies which did not differentiate the outcome data of solitary tumor and oligo-nodular tumor were also excluded.

\section{Data extraction}

All data were extracted using a standardized data extraction form. Relevant data were carefully extracted from each included study which is as listed: first author, publication year, country, study design, recorded tumor size, therapy and comparable outcomes. Outcomes that were used to compare were, 1-3-5 years overall survival rate and diseases free survival with their total tumor number comparing with their events. The assessment of quality of all included studies for meta-analysis was performed based on the Newcastle-Ottawa scale by determining the selection of participants, the comparability and the outcome.

\section{Statistical analysis}

In systematic review, qualitative data assessing 1-3 and 5-year overall survival and diseases free survival ratio with tumor number were analyzed using chi square test.
Furthermore, meta-analysis was performed using Review manager 5.3 software (Cochrane Library) for all statistical analysis. $P$ value $\leq 0.05$ was considered statistically significant for all statistical analyses. Odd ratio (OR) was considered as effect estimates and along with its corresponding 95\% CI was used to perform metaanalysis. Heterogeneity among studies was examined by $\mathrm{I}^{2}$ statistics.

Publication bias was assessed using the visual inspection of funnel plots, the Begs rank correlation method and the Egger weighted regression method $(p<0.05$ was considered statistically significant publication bias). Fill and trim method were used if a publication bias existed.

\section{RESULTS}

The total eighteen studies (14 NRCT studies and 4 RCT trials) eligible manuscripts included a total of 4,823 patients in which the resection group included 2,564 cases and the RFA group included 2,259 cases. We compared the outcome differences between the patients with a small solitary HCC and small oligonodular HCC. Overall survival rates at 1, 3 and 5 year in the HR group small solitary HCC sub-group were $93.9 \%, 81.3 \%$ and $72.0 \%$, and small oligonodular HCC sub-group were $83.3 \%, 70.4 \%$ and $45.4 \%$ respectively. The 1,3 and 5 years OR values for small solitary HCC sub-group and small oligonoular HCC sub-group were 3.88 (95\% CI: 1.63-9.22), 2.53 (95\% CI: 1.33-4.82), 4.31 (95\% CI: 1.92-9.68), $(\mathrm{p}<0.00001)$. The corresponding diseases free survival rates at 1,3 and 5 year in the HR group small solitary HCC sub-group were $76.4 \%, 56.0 \%$ and $44.0 \%$ and small oligonodular HCC sub-group were $65.9 \%$. $40.7 \%$ and $11.1 \%$ respectively. The 1,3 and 5 years OR values of small solitary HCC sub-group and small oligonodular HCC sub-group were 1.92 (95\% CI: $1.83-$ 4.46), 2.05 (95\% CI: 1.02-4.12), 4.32 (95\% CI: 2.567.29), ( $<<0.00001)$. The overall survival rates for RFA group small solitary HCC sub-group were $91.2 \%, 74.1 \%$ and $54.5 \%$ and small oligonodular HCC sub-group were $82.0 \%, 55.4 \%$ and $38.2 \%$ respectively. The 1-, 3-, and 5year OR values for small solitary HCC sub-group and small oligonodular HCC sub-group were 2.28 (95\% CI: 1.98-5.30), 2.28 (95\% CI: 1.37-3.80), 2.49 (95\% CI: 1.25-4.94), $(\mathrm{p}<0.00001)$. However, the corresponding diseases free survival rates for RFA group small solitary HCC sub-group were $74.1 \%, 49.8 \%$ and $22.1 \%$ and small oligonodular HCC sub-group were $62.6 \%, 37.3 \%$ and $8.2 \%$ respectively. The 1,3 and 5 years OR values of small solitary HCC sub-group and small oligonodular tumor sub-group were 3.01 (95\% CI: 1.91-9.92), 1.92 $(95 \% \quad$ CI: $1.34-2.76), \quad 3.03 \quad(95 \%$ CI: $1.04-8.79)$, $(\mathrm{p}<0.0001)$.

Included studies were mainly conducted in China (13), Japan (2), Italy (2), and Korea (1). Table 1 shows the baseline characteristics of the final included studies. Table 2 shows summary of the results on long term 
efficiency of HR versus RFA in treatment of small solitary HCC and small oligonodular HCC.

This is risk bias graph and bias summary table of four RCTs which shows low risk bias in our study and there is no high-risk bias. ${ }^{2-5}$ In cohort study the average grade is 7 or 8 which shows low risk bias in our study (Figure 2 and 3 ).

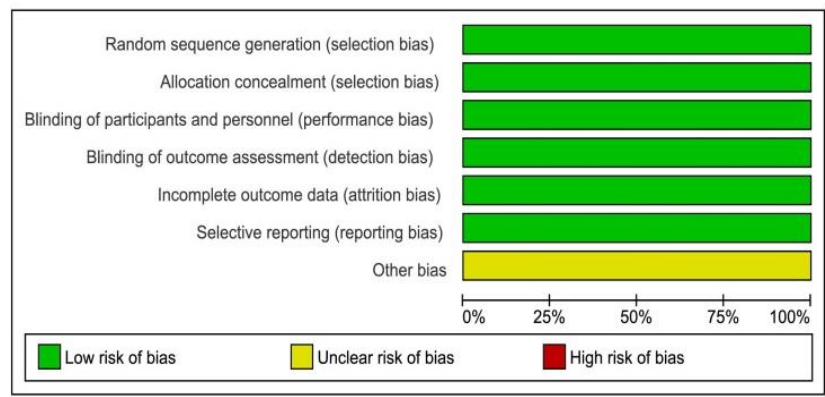

Figure 2: Risk of bias graph- review authors' judgement about each risk of bias item presented as percentages across all included studies.

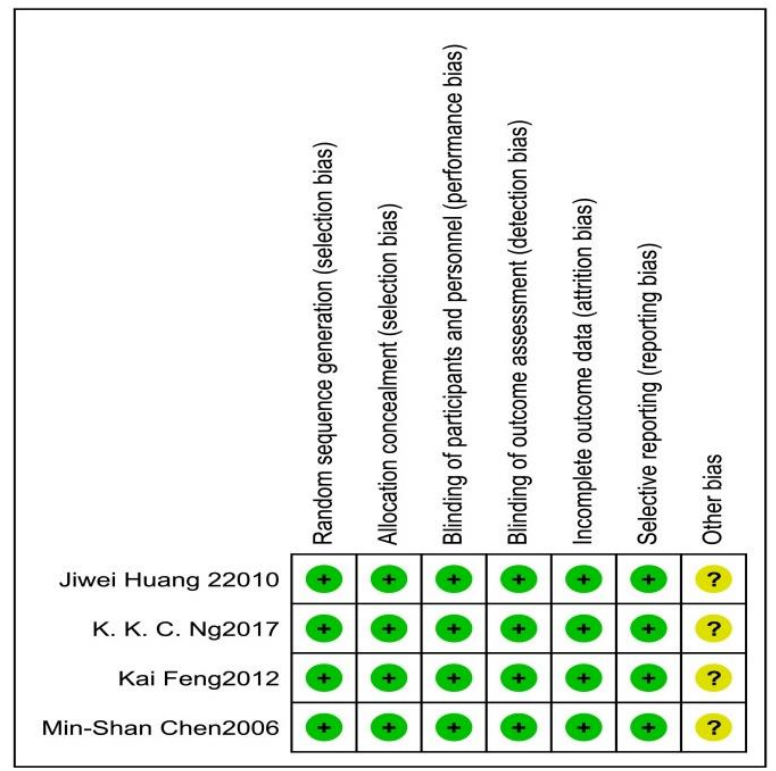

Figure 3: Risk of bias summary- review authors' judgement about each risk of bias item for each included study.

Table 1: Baseline characteristics of included studies $(n=18)$.

\begin{tabular}{|c|c|c|c|c|c|c|c|c|c|}
\hline Author & Year & Study & Country & Enroll period & Threapy & No. pts & $\begin{array}{l}\text { Tumor } \\
\text { solitary/ } \\
\text { oligonodular }\end{array}$ & $\begin{array}{l}\text { Tumor size } \\
\text { (Mean } \pm \text { SD, } \\
\text { cm) }\end{array}$ & Grade \\
\hline \multirow{2}{*}{$\begin{array}{l}\text { Tashiro } \\
\text { et al }^{6}\end{array}$} & \multirow{2}{*}{2011} & \multirow{2}{*}{ NRCT } & \multirow{2}{*}{ Japan } & \multirow{2}{*}{ 2001-2007 } & HR & 199 & $132 / 67$ & $2.1 \pm 0.6$ & \multirow{2}{*}{7} \\
\hline & & & & & RFA & 87 & $67 / 20$ & $1.8 \pm 0.52$ & \\
\hline \multirow{2}{*}{$\begin{array}{l}\text { Min } \\
\text { et } \text { al }^{7}\end{array}$} & \multirow{2}{*}{2018} & \multirow{2}{*}{ NRCT } & \multirow{2}{*}{ Korea } & \multirow{2}{*}{ 2004-2009 } & HR & 26 & $0 / 26$ & $\leq 3$ & \multirow{2}{*}{6} \\
\hline & & & & & RFA & 62 & $0 / 62$ & $\leq 3$ & \\
\hline \multirow{2}{*}{$\begin{array}{l}\text { Desiderio } \\
\text { et al }{ }^{9}\end{array}$} & \multirow{2}{*}{2012} & \multirow{2}{*}{ NRCT } & \multirow{2}{*}{ Italy } & \multirow{2}{*}{ 2004-2012 } & HR & 52 & $22 / 18$ & $\leq 3$ & \multirow{2}{*}{7} \\
\hline & & & & & RFA & 44 & $19 / 13$ & $\leq 3$ & \\
\hline \multirow{2}{*}{$\begin{array}{l}\text { Huang } \\
\text { et } \mathbf{a l}^{2}\end{array}$} & \multirow{2}{*}{2010} & \multirow{2}{*}{ RCT } & \multirow{2}{*}{ China } & \multirow{2}{*}{ 2003-2005 } & HR & 115 & $44 / 26$ & $\leq 3$ & \\
\hline & & & & & RFA & 115 & $27 / 31$ & $\leq 3$ & \\
\hline \multirow{2}{*}{$\begin{array}{l}\mathrm{Ng} \\
\text { et } \mathrm{al}^{3}\end{array}$} & \multirow{2}{*}{2017} & \multirow{2}{*}{ RCT } & \multirow{2}{*}{ China } & \multirow{2}{*}{ 2002-2007 } & HR & 109 & $29 / 7$ & $2 \cdot 9(1-5)$ & \\
\hline & & & & & RFA & 109 & $26 / 15$ & $2 \cdot 6(1-5)$ & \\
\hline \multirow{2}{*}{$\begin{array}{l}\text { Feng } \\
\text { et } \text { al }^{4}\end{array}$} & \multirow{2}{*}{2012} & $\mathrm{PCT}$ & Ching & 20052008 & HR & 84 & $52 / 32$ & $\leq 5$ & \\
\hline & & KCl & Cnina & $2005-2008$ & RFA & 84 & $48 / 36$ & & \\
\hline Jiang & 2015 & NPCT & Ching & 20002012 & HR & 224 & $0 / 181$ & $2.5 \pm 0.6$ & 7 \\
\hline et $\mathbf{a l}^{19}$ & 2015 & NRCI & Cnina & $2008-2013$ & RFA & 160 & $0 / 110$ & $2.3 \pm 0.6$ & 1 \\
\hline Vivarelli & 2004 & NRCT & Italy & 1998_2007 & HR & 79 & $17 / 2$ & $\leq 3$ & \\
\hline et $\mathbf{a l}^{9}$ & 2004 & NRCI & Italy & $1998-2002$ & RFA & 79 & $6 / 5$ & $\leq 3$ & 8 \\
\hline Chen & 2006 & $\mathrm{RCT}$ & Ching & $1009-2004$ & HR & 90 & $69 / 16$ & $\leq 5$ & \\
\hline et $\mathbf{a l}^{10}$ & 2006 & $\mathrm{KCl}$ & Cnina & 1999-2004 & RFA & 71 & $56 / 14$ & & \\
\hline Poon & 2001 & NDCT & Ching & 10801000 & HR & 473 & $115 / 20$ & $3.2 \pm 1.1$ & 8 \\
\hline et $\mathbf{a l}^{11}$ & 2001 & NKC 1 & Cnma & $1989-1999$ & RFA & 0 & 0 & & 0 \\
\hline Fan & 2011 & NPCT & Ching & 1005-2008 & HR & 408 & $384 / 24$ & $\leq 3$ & 8 \\
\hline et $\mathbf{a l}^{12}$ & 2011 & NRCI & China & $1995-2008$ & RFA & 0 & 0 & & 8 \\
\hline Ueno & 2000 & NRCT & Janan & 2000_2005 & HR & 123 & $78 / 13$ & $2.7 \pm 0.1$ & 7 \\
\hline et $\mathbf{a l}^{13}$ & 2009 & NKC 1 & Japan & $2000-2005$ & RFA & 155 & $92 / 54$ & $2.0 \pm 0.1$ & 7 \\
\hline & 2015 & NDCT & Ching & 20002012 & HR & 97 & $0 / 91$ & $2.4 \pm 0.6$ & 8 \\
\hline et $\mathbf{a l}^{14}$ & 2015 & NKCI & Cnina & $2009-2013$ & RFA & 0 & 0 & & $\gamma$ \\
\hline He & 2016 & NRCT & Ching & 20013_2013 & HR & 310 & $86 / 12$ & $3.3 \pm 1.0$ & 8 \\
\hline et $\mathbf{a l}^{15}$ & 2010 & NKC 1 & Cnina & $2001-2013$ & RFA & 125 & $72 / 10$ & $2.6 \pm 1.0$ & 8 \\
\hline
\end{tabular}




\begin{tabular}{|c|c|c|c|c|c|c|c|c|c|}
\hline Author & Year & Study & Country & Enroll period & Threapy & No. pts & $\begin{array}{l}\text { Tumor } \\
\text { solitary/ } \\
\text { oligonodular }\end{array}$ & $\begin{array}{l}\text { Tumor size } \\
(\text { Mean } \pm \text { SD, } \\
\text { cm) }\end{array}$ & Grade \\
\hline \multirow{2}{*}{$\begin{array}{l}\text { Guo } \\
\text { et } \mathbf{a l}^{17}\end{array}$} & \multirow{2}{*}{2012} & \multirow{2}{*}{ NRCT } & \multirow{2}{*}{ China } & \multirow{2}{*}{ 2002-2007 } & HR & 102 & $75 / 27$ & $\leq 3$ & \multirow[b]{2}{*}{7} \\
\hline & & & & & RFA & 94 & $63 / 31$ & $\leq 3$ & \\
\hline \multirow{2}{*}{$\begin{array}{l}\text { Guo } \\
\text { et } \text { al }^{18}\end{array}$} & \multirow{2}{*}{2010} & \multirow{2}{*}{ NRCT } & \multirow{2}{*}{ China } & \multirow{2}{*}{$2002-2007$} & HR & 73 & $0 / 64$ & $\leq 3$ & \multirow[b]{2}{*}{7} \\
\hline & & & & & RFA & 86 & $0 / 47$ & $3.1-5$ & \\
\hline \multirow{2}{*}{$\begin{array}{l}\text { Chen } \\
\text { et } \mathbf{a l}^{10}\end{array}$} & \multirow{2}{*}{2005} & \multirow{2}{*}{ NRCT } & \multirow{2}{*}{ China } & \multirow{2}{*}{ 1999-2005 } & HR & 0 & 0 & & \multirow[b]{2}{*}{7} \\
\hline & & & & & RFA & 256 & $151 / 105$ & $\leq 3$ & \\
\hline \multirow{2}{*}{$\begin{array}{l}\text { Yang } \\
\text { et } \mathbf{a l}^{16}\end{array}$} & \multirow{2}{*}{2016} & \multirow{2}{*}{ NRCT } & \multirow{2}{*}{ China } & \multirow{2}{*}{$2000-2013$} & HR & 0 & 0 & & \multirow[b]{2}{*}{6} \\
\hline & & & & & RFA & 732 & $248 / 68$ & $\leq 3$ & \\
\hline
\end{tabular}

Abbreviations: HR, Hepatic resection; RFA, Radiofrequency ablation; RCT, Randomized control trials; NRCT, Non-randomized control trials.

Table 2: Summary of the results on long term efficiency of hepatic resection versus radio frequency ablation in treatment of solitary tumor and oligonodular tumor.

\begin{tabular}{|c|c|c|c|c|c|c|}
\hline Outcomes & $\begin{array}{l}\text { No. of } \\
\text { studies }\end{array}$ & $\begin{array}{l}\text { No. pts } \\
\text { solitary }\end{array}$ & $\begin{array}{l}\text { No.pts } \\
\text { oligonodular }\end{array}$ & $\begin{array}{l}\text { Solitary } \\
(\%)\end{array}$ & $\begin{array}{l}\text { Oligonodular } \\
(\%)\end{array}$ & Odd ratio $(95 \%$ CI) \\
\hline \multicolumn{7}{|c|}{ Hepatic resection group } \\
\hline \multicolumn{7}{|c|}{ Overall survival } \\
\hline 1 year & 12 & $1036 / 1103$ & $220 / 264$ & 93.90 & 83.30 & $3.88(1.63-9.22)$ \\
\hline 3 year & 12 & $897 / 1103$ & $186 / 264$ & 81.30 & 70.40 & $2.53(1.33-4.82)$ \\
\hline 5 year & 8 & $641 / 890$ & $85 / 187$ & 72.00 & 45.40 & $4.31(1.92-9.68)$ \\
\hline \multicolumn{7}{|c|}{ Diseases free survival } \\
\hline 1 year & 11 & $810 / 1059$ & $157 / 238$ & 76.40 & 65.90 & $1.92(1.83-4.46)$ \\
\hline 3 year & 11 & $594 / 1059$ & $97 / 238$ & 56.00 & 40.70 & $2.05(1.02-4.12)$ \\
\hline 5 year & 7 & $373 / 846$ & $18 / 161$ & 44.00 & 11.00 & $4.32(2.56-7.29)$ \\
\hline \multicolumn{7}{|l|}{ RFA group } \\
\hline \multicolumn{7}{|c|}{ Overall survival } \\
\hline 1 year & 12 & $798 / 875$ & $330 / 402$ & 91.20 & 82.00 & $2.28(1.98-5.30)$ \\
\hline 3 year & 12 & $649 / 875$ & $223 / 402$ & 74.10 & 55.40 & $2.28(1.37-3.80)$ \\
\hline 5 year & 8 & $383 / 702$ & $121 / 316$ & 54.50 & 38.20 & $2.49(1.25-4.94)$ \\
\hline \multicolumn{7}{|c|}{ Diseases free survival } \\
\hline 1 year & 9 & $333 / 449$ & $124 / 198$ & 74.10 & 62.60 & $3.01(1.91-9.92)$ \\
\hline 3 year & 9 & $224 / 449$ & $74 / 198$ & 49.80 & 37.30 & $2.12(1.12-3.99)$ \\
\hline 5 year & 5 & $61 / 276$ & $10 / 112$ & 22.10 & 8.20 & $3.03(1.04-8.79)$ \\
\hline
\end{tabular}

\section{Data synthesis}

1, 3 and 5 year OS of the patients undergoing HR of the small solitary HCC sub-group and small oligonodular HCC sub-group

Twelve studies reported data related to the 1, 3 and 5 year overall survival of the patients with small HCC undergoing hepatic resection. ${ }^{2-6,8,9,11-13,15,18}$ Our analyses show that the 1,3 and 5 year overall survival of the patients undergoing hepatic resection in the small solitary HCC and small oligonodular HCC sub-group was that the small solitary HCC sub-group had a better survival compared to the small oligonodular HCC group. Where $\mathrm{p} \leq 0.00001$, which is statistically significant. Overall survival rates at 1,3 and 5 years in the HR group small solitary HCC sub-group were $93.9 \%, 81.3 \%$ and $72.0 \%$ and small oligonodular HCC sub-group were $83.3 \%$, $70.4 \%$ and $45.4 \%$. Where $[\mathrm{M}-\mathrm{H}=3.88,95 \% \mathrm{CI}$ of $(1.63-$ 9.22), $\left.\mathrm{p}=0.009, \mathrm{I}^{2}=56 \%\right],[\mathrm{M}-\mathrm{H}=2.53,95 \% \mathrm{CI}$ of $(1.33-$
4.82), $\left.\mathrm{p}=0.003, \mathrm{I}^{2}=61 \%\right],[\mathrm{M}-\mathrm{H}=4.31,95 \%$ CI of $(1.92-$ 9.68), $\mathrm{p}=0.002, \mathrm{I}^{2}=69 \%$ ] respectively. Random effect was used for this meta-analysis (Figure 4-6).

1, 3 and 5 year DFS of the patients undergoing HR for small solitary HCC sub-group and small oligonodular HCC sub-group.

Eleven studies reported data for 1, 3 and 5 year diseases free survival of the patients undergoing hepatic resection between small solitary HCC and small oligo-nodular HCC. ${ }^{3-6,8,9,11-13,15,18}$ Our analyses showed that the small solitary HCC sub-group had a better diseases free survival compared to the small oligonodular HCC subgroup. Where $\mathrm{p} \leq 0.00001$, which is statistically significant. Diseases free survival rates at 1, 3 and 5 years in the LR group small solitary HCC sub-group were $76.4 \%, 56.0 \%$ and $44.0 \%$ and small oligonodular HCC sub-group were $65.9 \%$. $40.7 \%$ and $11.1 \%$. Where [M$\mathrm{H}=1.92,95 \% \mathrm{CI}$ of $\left.(1.83-4.46), \mathrm{p} \leq 0.00001, \mathrm{I}^{2}=76 \%\right]$, [M- 
$\mathrm{H}=2.05,95 \% \mathrm{CI}$ of (1.02-4.12), $\left.\mathrm{p}=0.0003, \mathrm{I}^{2}=70 \%\right]$, [M$\mathrm{H}=4.32,95 \% \quad \mathrm{CI}$ of $\left.(2.56-7.29), \quad \mathrm{p}=0.43, \quad \mathrm{I}^{2}=0 \%\right]$ respectively. Random effect was used for this metaanalysis (Figure 7-9).

1, 3 and 5 year OS of patients undergoing RFA between small solitary HCC sub-group and small oligonodular HCC sub-group

Twelve studies reported data for 1,3 and 5 year overall survival of patients undergoing radiofrequency ablation in the small solitary HCC and small oligonodular HCC. ${ }^{2-}$ 6,8-10,13,15,16,18 Our analyses showed that the small solitary HCC sub-group had a better survival compared to the small oligonodular HCC sub-group. Where $\mathrm{p} \leq 0.00001$, which is statistically significant. Overall survival rates at 1,3 and 5 years in the RFA groupsmall solitary HCC sub-group were $91.2 \%, 74.1 \%$ and $54.5 \%$ and small oligonodular HCC sub-group were $82.0 \%, 55.4 \%$ and $38.2 \%$. Where $[\mathrm{M}-\mathrm{H}=2.28,95 \%$ CI of $(1.98-5.30)$, $\left.\mathrm{p}=0.00010, \mathrm{I}^{2}=65 \%\right],[\mathrm{M}-\mathrm{H}=2.28,95 \% \mathrm{CI}$ of $(1.37-3.80)$, $\left.\mathrm{p}=0.006, \mathrm{I}^{2}=56 \%\right],[\mathrm{M}-\mathrm{H}=2.49,95 \% \mathrm{CI}$ of $(1.25-4.94)$, $\mathrm{p}=0.00005, \mathrm{I}^{2}=73 \%$ ] respectively. Random effect was used for this meta-analysis (Figure 10-12).

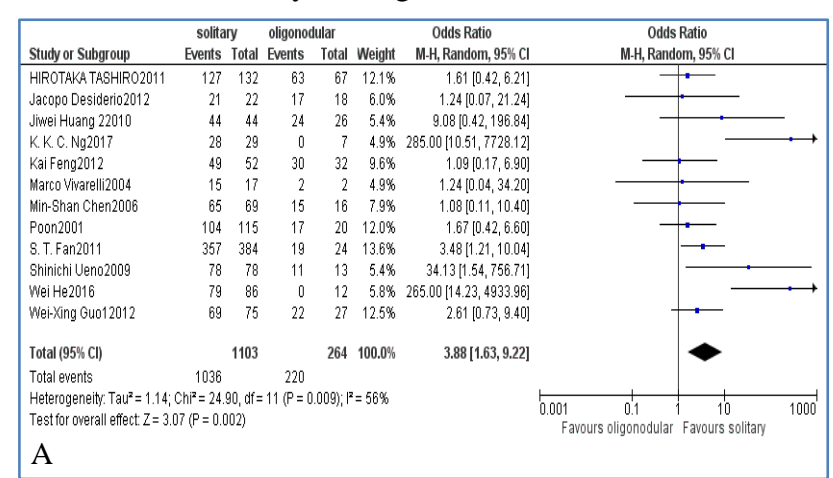

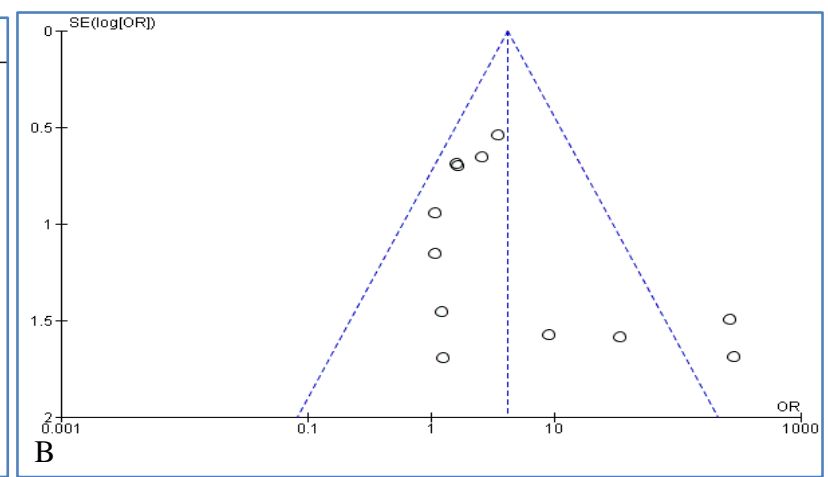

Figure 4: (A) Comparison of the 1-year overall survival rate between small solitary HCC and small oligonodular HCC in Hepatic resection. CI, confidence interval; M-H, Mantel-Haenszel; (B) Funnel plot of standard error by log odd ratio for small solitary HCC and small oligonodular HCC.

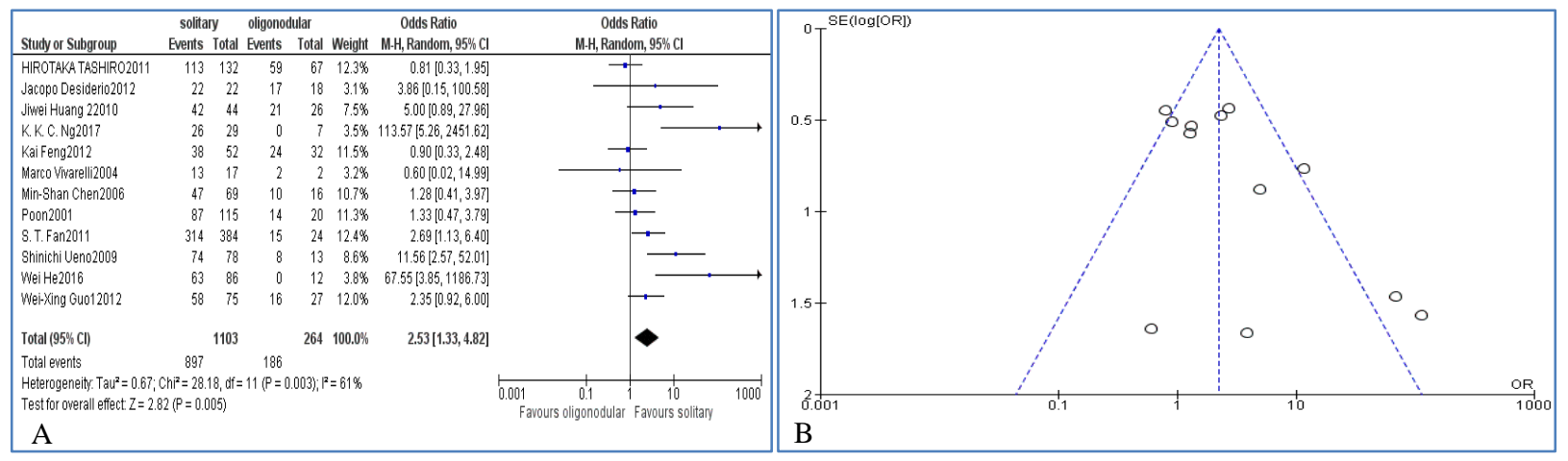

Figure 5: (A) Comparison of the 3-year overall survival rate between small solitary HCC and small oligonodular HCC in Hepatic resection. CI, confidence interval; M-H, Mantel-Haenszel; (B) Funnel plot of standard error by log odd ratio for small solitary HCC and small oligonodular HCC. 


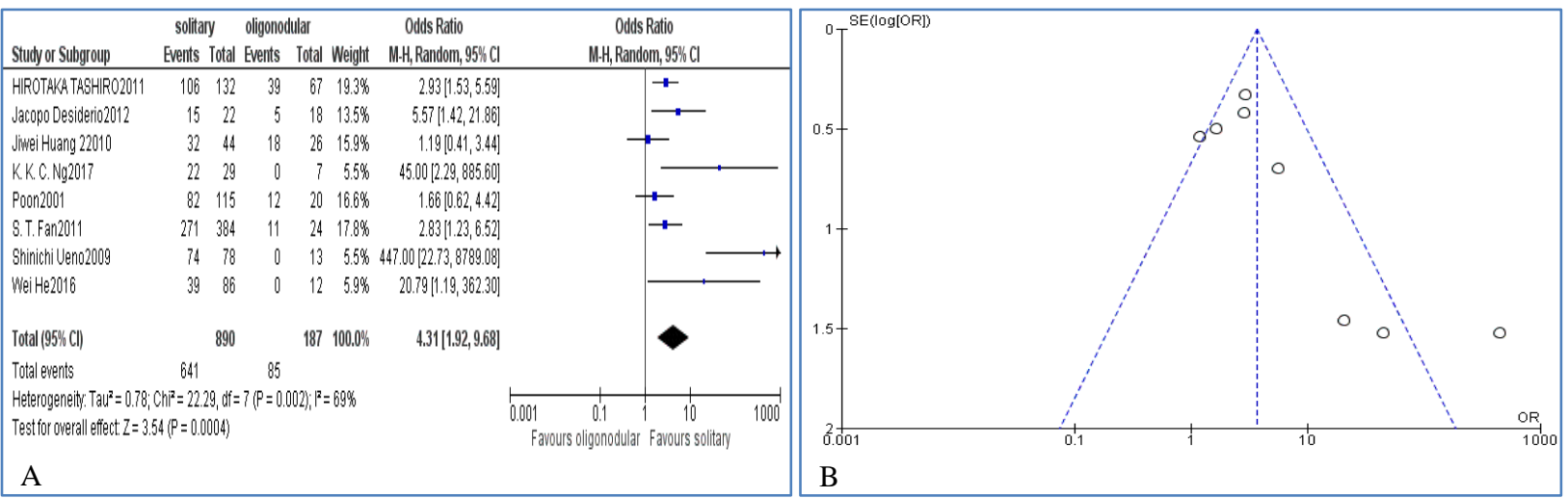

Figure 6: (A) Comparison of the 5-year overall survival rate between small solitary HCC and small oligonodular HCC in Hepatic resection. CI, confidence interval; M-H, Mantel-Haenszel; (B) Funnel plot of standard error by log odd ratio for small solitary HCC and small oligonodular HCC.

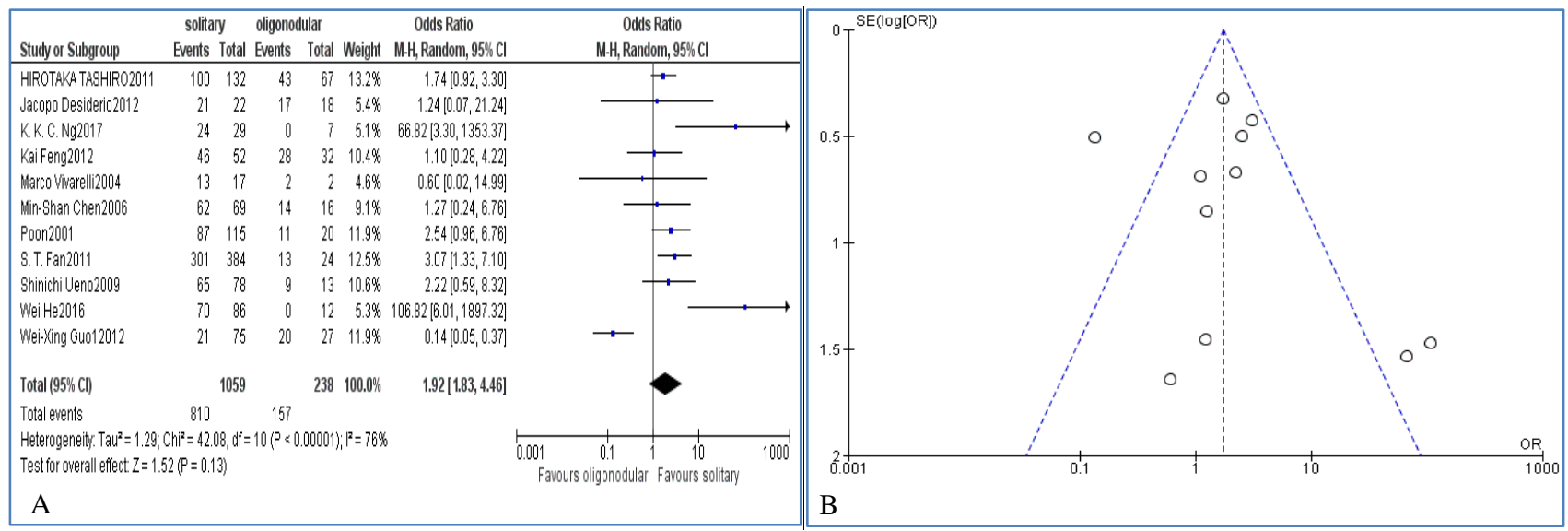

Figure 7: (A) Comparison of the 1-year diseases free survival rate between small solitary HCC and small oligonodular HCC in Hepatic resection. CI, confidence interval; M-H, Mantel-Haenszel; (B) Funnel plot of standard error by log odd ratio for small solitary HCC and small oligonodular HCC.

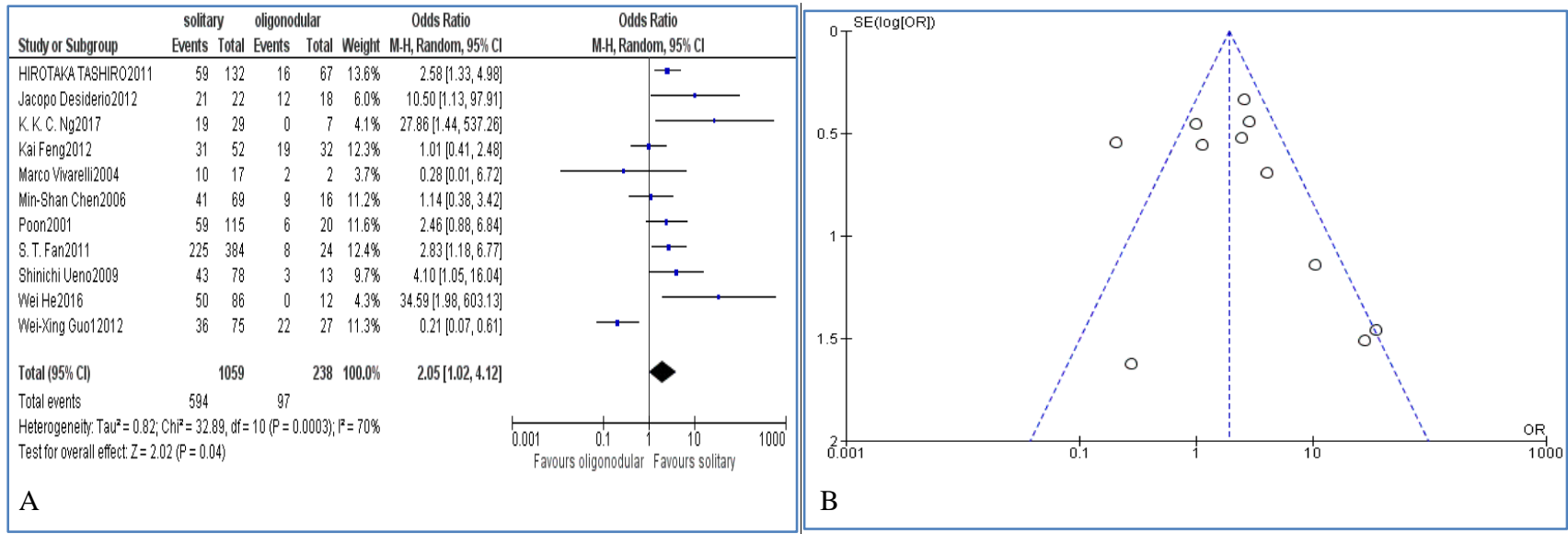

Figure 8: (A) Comparison of the 3-year diseases free survival rate between small solitary HCC and small oligonodular HCC in Hepatic resection. CI, confidence interval; M-H, Mantel-Haenszel; (B) Funnel plot of standard error by log odd ratio for small solitary HCC and small oligonodular HCC. 


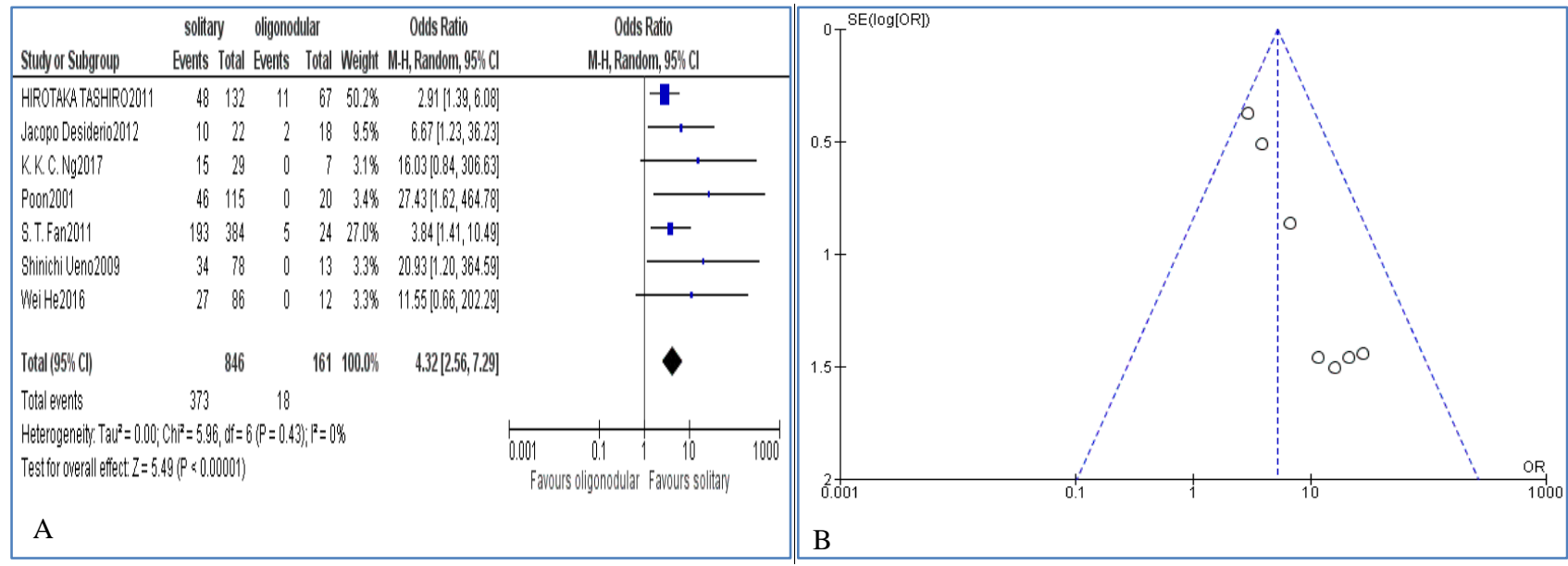

Figure 9: (A) Comparison of the 5-year diseases free survival rate between small solitary HCC and small oligonodular HCC in Hepatic resection. CI, confidence interval; M-H, Mantel-Haenszel; (B) Funnel plot of standard error by $\log$ odd ratio for small solitary HCC and small oligonodular HCC.

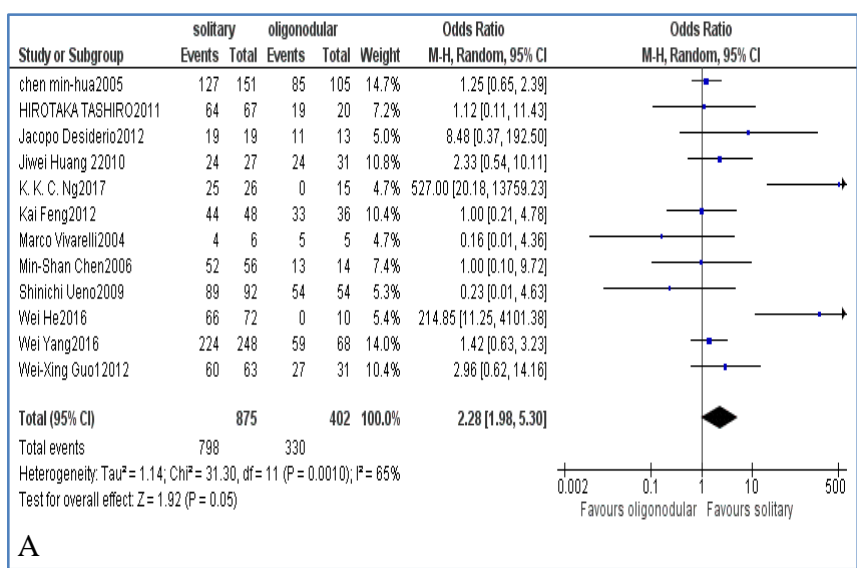

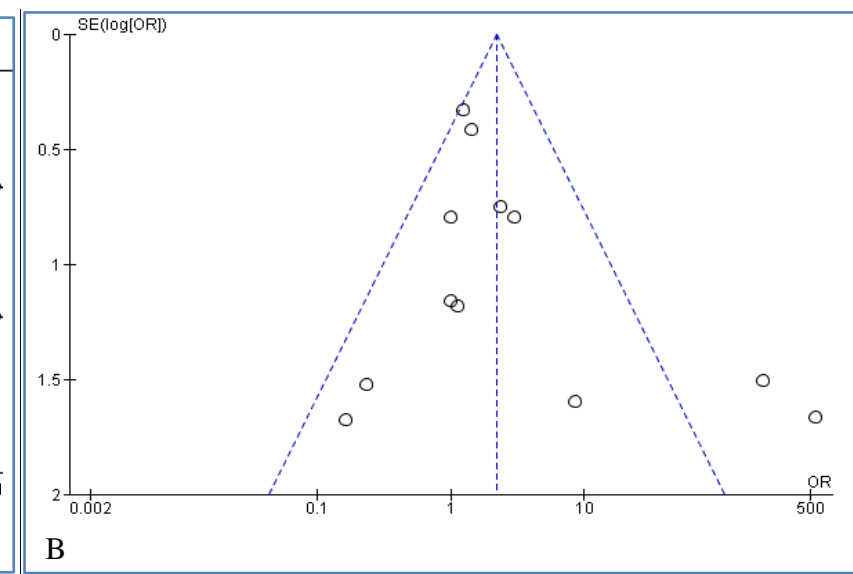

Figure 10: (A) Comparison of the 1-year overall survival rate between small solitary HCC and small oligonodular HCC in RFA. CI, confidence interval; M-H, Mantel-Haenszel; (B) Funnel plot of standard error by log odd ratio for small solitary HCC and small oligonodular HCC.

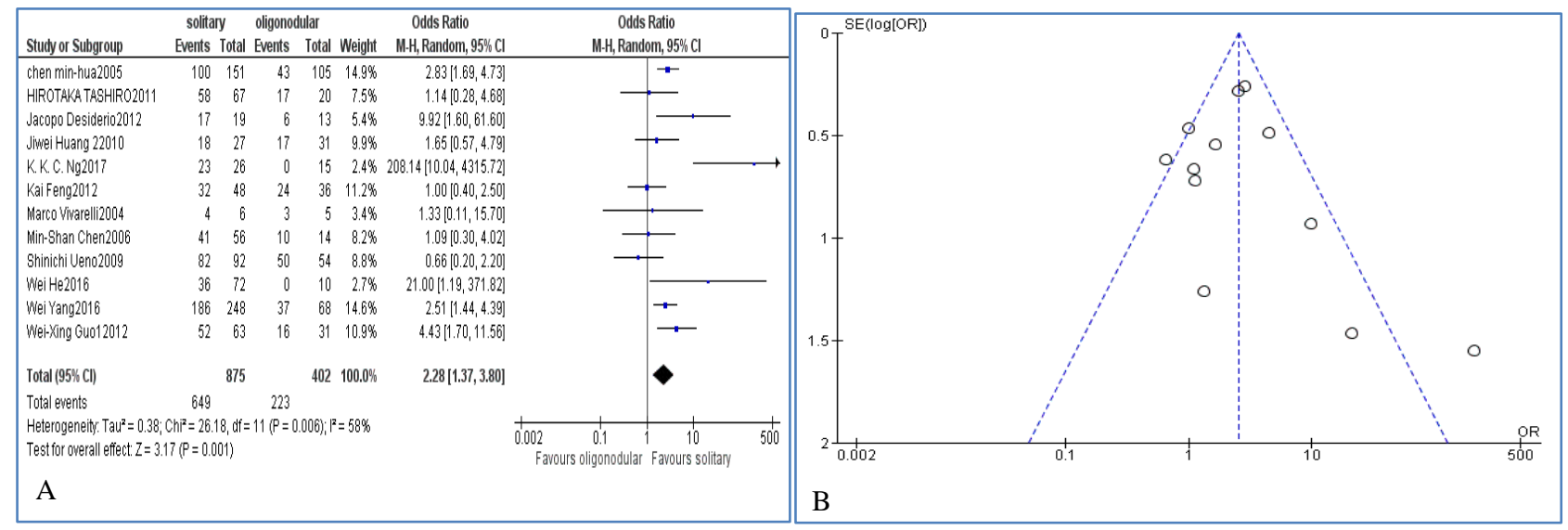

Figure 11: (A) Comparison of the 3-years overall survival rate between small solitary HCC and small oligonodular HCC in RFA. CI, confidence interval; M-H, Mantel-Haenszel; (B) Funnel plot of standard error by log odd ratio for small solitary HCC and small oligonodular HCC. 


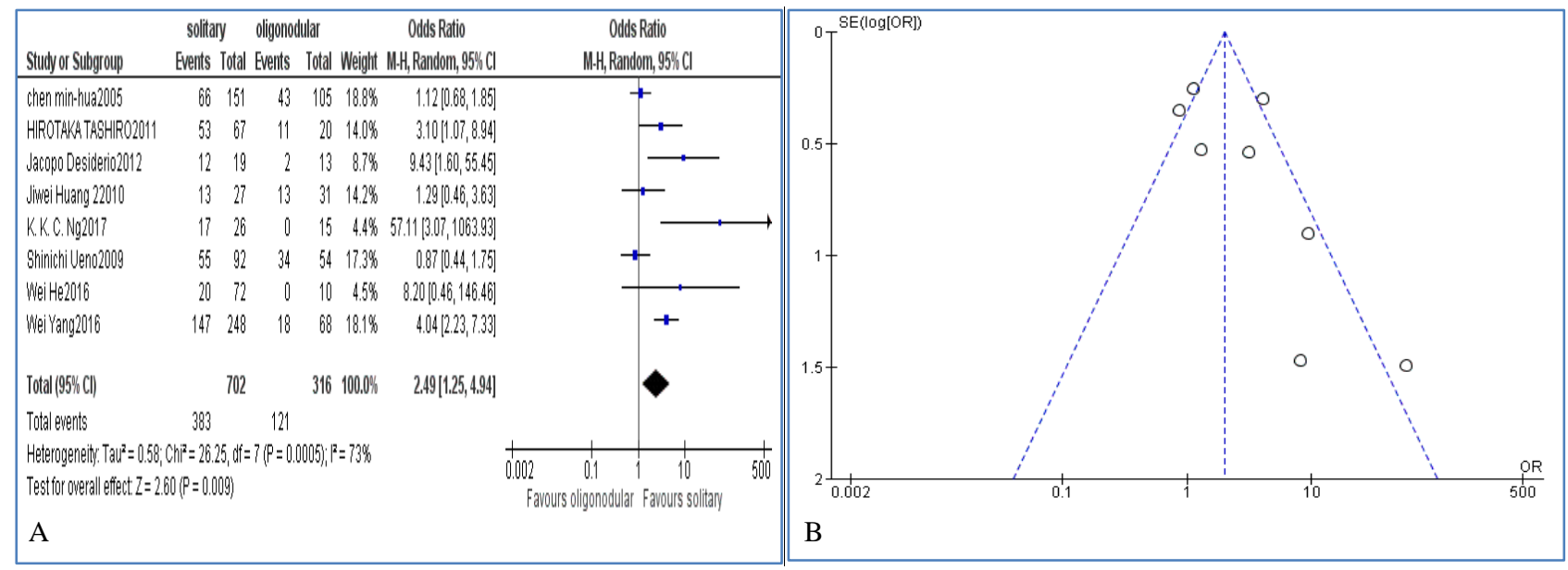

Figure 12: (A) Comparison of the 5-years overall survival rate between small solitary HCC and small oligonodular HCC in RFA. CI, confidence interval; M-H, Mantel-Haenszel; (B) Funnel plot of standard error by log odd ratio for small solitary HCC and small oligonodular HCC.

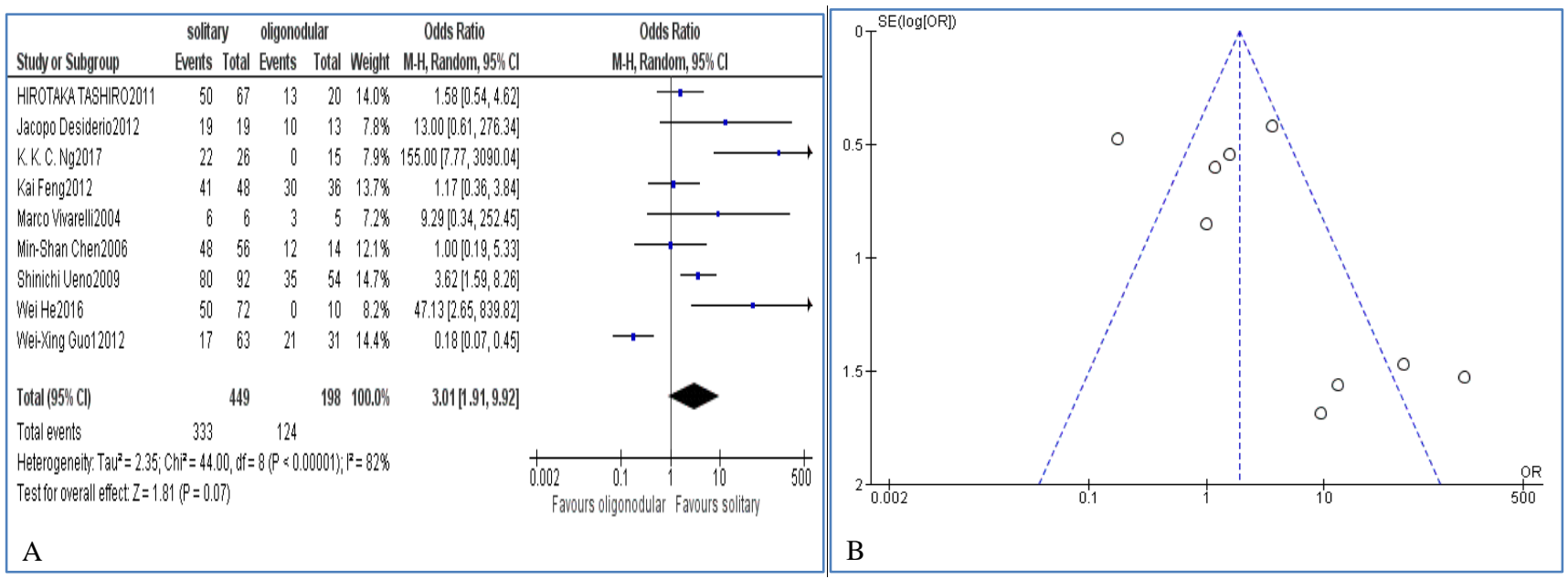

Figure 13: (A) Comparison of the 1-year diseases free survival rate between small solitary HCC and small oligonodular HCC in RFA. CI, confidence interval; M-H, Mantel-Haenszel; (B) Funnel plot of standard error by log odd ratio for small solitary HCC and small oligonodular HCC.

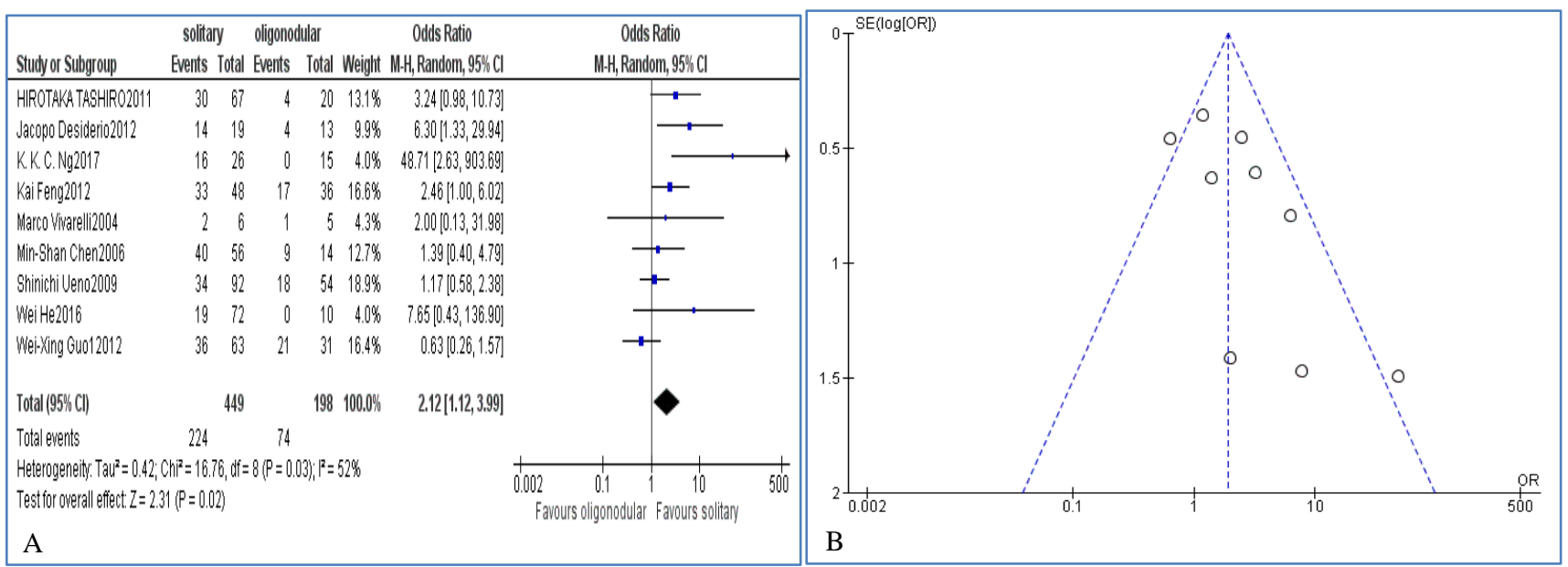

Figure 14: (A) Comparison of the 3-years diseases free survival rate between small solitary HCC and small oligonodular HCC in RFA. CI, confidence interval; M-H, Mantel-Haenszel. (B) Funnel plot of standard error by odd ratio for small solitary HCC and small oligonodular HCC. 


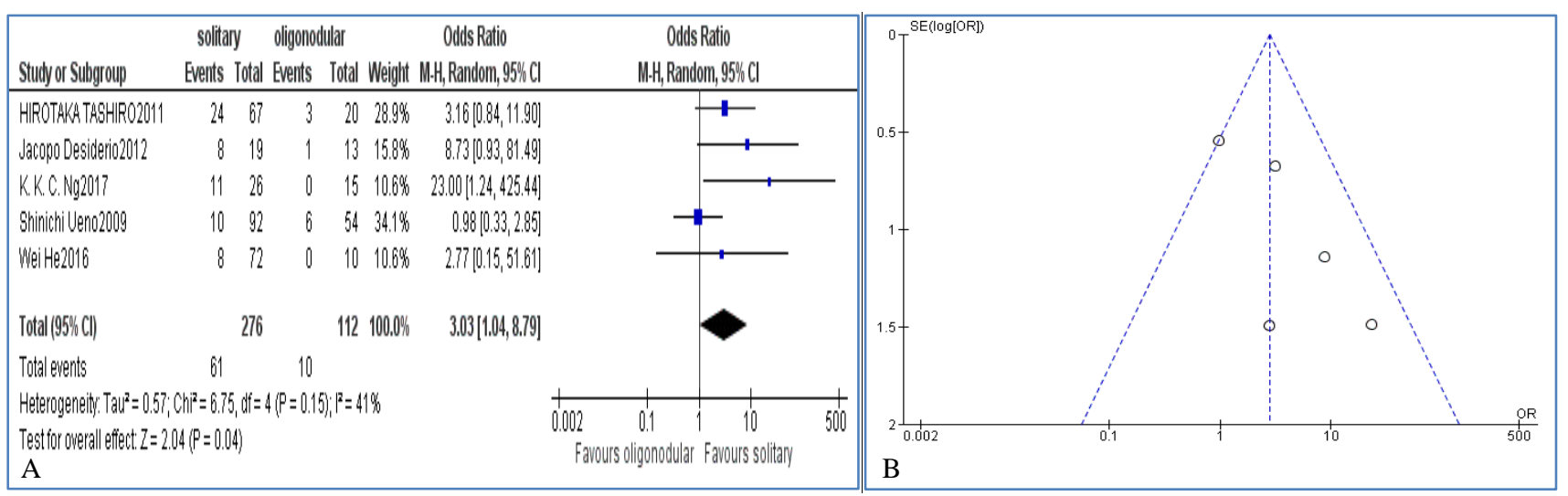

Figure 15: (A) Comparison of the 5-years diseases free survival rate between small solitary HCC and small oligonodular HCC in RFA. CI, confidence interval; M-H, Mantel-Haenszel. (B) Funnel plot of standard error by log odd ratio for small solitary HCC and small oligonodular HCC.

\section{DISCUSSION}

In this study, we compared the OS and DFS differences of the patients with HCC meeting Milan criteria between small solitary HCC and small oligonodular HCC after hepatic resection or radiofrequency ablation. It is the first time to make meta-analyses to compare the survival difference between small solitary HCC and small oligonodular HCC after hepatic resection or radiofrequency ablation. It showed that patients with small solitary HCC had a better survival rate than those patients with small oligo-nodular HCC after hepatic resection or RFA. In the HR group, 1, 3 and 5-years OS of the small solitary HCC sub-group were $93.9 \%, 81.7 \%$, and $72.0 \%$, and the small oligonodular HCC sub-group were $81.8 \%, 69.9 \%$, and $45.4 \%$, respectively. For the DFS in the HR group, 1,3 and 5 years of the small solitary HCC sub-group were $75.6 \%, 55.9 \%$, and $44.0 \%$, and the small oligonodular HCC sub-group, were $62.6 \%$, $37.8 \%$, and $11.1 \%$ respectively. In the RFA group, 1,3 and 5 years OS of the small solitary HCC sub-group were $91.0 \%, 74.6 \%$, and $54.5 \%$, and the small oligonodular HCC sub-group were $80.1 \%, 54.3 \%$, and $38.2 \%$, respectively. For the DFS in the RFA group, 1, 3 and 5 years of the small solitary HCC sub-group were $71.0 \%$, $47.3 \%$, and $22.1 \%$, and $58.0 \%$ and $33.4 \%, 8.2 \%$ of the small oligonodular HCC sub-group, respectively.

There are many studies, including 4 RCTs, mainly aiming at the outcome difference between HR and RFA. ${ }^{2-5}$ The first RCT published in 2006, Chen et al did not identify outcome differences between HR and RFA for only small solitary HCC. ${ }^{5}$ The second RCT in 2010 Huang et al and Third RCT in $2017 \mathrm{Ng}$ et al suggested a survival advantage of surgical resection over RFA, and the outcome of small solitary HCC sub-group was better than that of small oligonodular HCC., ${ }^{2,3}$ Many other studies achieved the same conclusions. In 2012, Feng et al published results that showed percutaneous RFA was equivalent to surgical resection for overall survival, but it was associated with increased local recurrence because of the residual tumors. ${ }^{4}$
In fact, as early as 1979, Tang et al defined the small HCC, which including small solitary HCC not more than $5 \mathrm{~cm}$, and $2 \mathrm{HCCs}$ not more than $5 \mathrm{~cm}$ of the total diameter. ${ }^{20}$ In 1993, Bismuth et al published an article showing a better outcome of liver transplantation over liver resection for one or two HCC smaller than $3 \mathrm{~cm}^{21}$ Similarly in 2011, Fan et al showed that 5 year survival of single liver cancer resection meeting the Milan criteria was better (rate) than multiple liver cancer in the Milan standard $(70.7 \%$ and $46.0 \%)$, and noted that this multinodular liver cancer may benefit from liver transplantation. ${ }^{12}$ According to the data from Zhongshan Hospital of Fudan University, the China guideline published in 2016, the Milan criteria was divided into two subtypes named I a and I b, which also support our results.

The limitation of our study should be considered. Firstly, this meta-analysis included some variables such as diseases process, operative procedures, ablation, and operation duration which may have differed between the cases. Eighteen studies were included in this study. Secondly, among the total studies only 4 were RCTs, which may have compromised the statistical power. ${ }^{2-5}$ Nevertheless, our review mainly includes retrospective studies whose limitations are well known. Thirdly the majority of studies were from Asian countries because they have the highest prevalence of cancer cases then the Western countries. Finally, as mentioned above, overall considerable heterogeneity was absorbed in our study. Therefore, we expect that more researchers will perform large, well-designed randomized controlled trials to clarify which treatment is the most effective against HCC in solitary tumor and oligonodular tumor.

\section{CONCLUSION}

At present scenario, our meta-analysis showed that both OS and DFS of small solitary HCC sub -group were better than those of small oligonodular HCC sub-group meeting Milan criteria, whereas treated by HR or RFA. HR had a better prognosis than RFA for both small 
solitary HCC and small oligonodular HCC meeting Milan criteria.

Funding: This study was supported by grants from the National major project's researches (No. 2012ZX10002016) and Sichuan Province Science and Technology Project of China (No. 2017SZ0139).

Conflict of interest: None declared

Ethical approval: Not required

\section{REFERENCES}

1. Forner A, Llovet JM, Bruix J. Hepatocellular carcinoma. Lancet. 2012;379(9822):1245-55.

2. Huang J, Yan L, Cheng Z, Wu H, Du L, Wang J, et al. A randomized trial comparing radiofrequency ablation and surgical resection for HCC conforming to the Milan criteria. Ann Surg. 2010;252(6):90312.

3. Ng KKC, Chok KSH, Chan ACY, Cheung TT, Wong TCL, Fung JYY, et al. Randomized clinical trial of hepatic resection versus radiofrequency ablation for early-stage hepatocellular carcinoma. $\mathrm{Br}$ J Surg. 2017;104(13):1775-84.

4. Feng K, Yan J, Li X, Xia F, Ma K, Wang S, et al. A randomized controlled trial of radiofrequency ablation and surgical resection in the treatment of small hepatocellular carcinoma. J Hepatol. 2012;57(4):794-802.

5. Chen MS, Li JQ, Zheng Y, Guo RP, Liang HH, Zhang $\mathrm{YQ}$, et al. A prospective randomized trial comparing percutaneous local ablative therapy and partial hepatectomy for small hepatocellular carcinoma. Ann Surg. 2006;243(3):321-8.

6. Tashiro H, Aikata H, Waki K, Amano H, Oshita A, Kobayashi $\mathrm{T}$, et al. Treatment strategy for early hepatocellular carcinomas: comparison of radiofrequency ablation with or without transcatheter arterial chemoembolization and surgical resection. J Surg Oncol. 2011;104(1):3-9.

7. Min JH, Kang TW, Cha DI, Song KD, Lee MW, Rhim $\mathrm{H}$, et al. Radiofrequency ablation versus surgical resection for multiple HCCs meeting the Milan criteria: propensity score analyses of 10-year therapeutic outcomes. Clin Radiol. 2018;73(7):676 e15- e24.

8. Desiderio J, Trastulli S, Pasquale R, Cavaliere D, Cirocchi R, Boselli C, et al. Could radiofrequency ablation replace liver resection for small hepatocellular carcinoma in patients with compensated cirrhosis? A 5-year follow-up. Langenbecks Arch Surg. 2013;398(1):55-62.

9. Vivarelli M, Guglielmi A, Ruzzenente A, Cucchetti A, Bellusci R, Cordiano C, et al. Surgical resection versus percutaneous radiofrequency ablation in the treatment of hepatocellular carcinoma on cirrhotic liver. Ann Surg. 2004;240(1):102-7.

10. Chen MH, Yan K, Yang W, Gao W, Dai Y, Huo L, et al. Long term (5 years) outcome of radiofrequency ablation for hepatocellular carcinoma in 256 cases. Beijing Da Xue Xue Bao Yi Xue Ban. 2005;37(6):671-2.

11. Fan ST, Poon RT, Yeung C, Lam CM, Lo CM, Yuen WK, et al. Outcome after partial hepatectomy for hepatocellular cancer within the Milan criteria. Br J Surg. 2011;98(9):1292-300.

12. Fan ST, Mau Lo C, Poon RT, Yeung C, Leung Liu $\mathrm{C}$, Yuen WK, et al. Continuous improvement of survival outcomes of resection of hepatocellular carcinoma: a 20-year experience. Ann Surg. 2011;253(4):745-58.

13. Ueno S, Sakoda M, Kubo F, Hiwatashi K, Tateno T, Baba Y, et al. Surgical resection versus radiofrequency ablation for small hepatocellular carcinomas within the Milan criteria. J Hepatobiliary Pancreat Surg. 2009;16(3):359-66.

14. Lv T, Jiang L, Yan L, Yang J, Li B, Wen T, et al. Multiple Tumors Located in the Same Section Are Associated with Better Outcomes After Hepatic Resection for HCC Patients Meeting the Milan Criteria. J Gastrointest Surg. 2015;19(12):2207-14.

15. He W, Li B, Zheng Y, Zou R, Shen J, Cheng D, et al. Resection vs. ablation for alpha-fetoprotein positive hepatocellular carcinoma within the Milan criteria: a propensity score analysis. Liver Int. 2016;36(11):1677-87.

16. Yang W, Yan K, Goldberg SN, Ahmed M, Lee JC, $\mathrm{Wu} \mathrm{W}$, et al. Ten-year survival of hepatocellular carcinoma patients undergoing radiofrequency ablation as a first-line treatment. World $\mathbf{J}$ Gastroenterol. 2016;22(10):2993-3005.

17. Guo WX, Zhai B, Lai EC, Li N, Shi J, Lau WY, et al. Percutaneous radiofrequency ablation versus partial hepatectomy for multicentric small hepatocellular carcinomas: a nonrandomized comparative study. World J Surg. 2010;34(11):2671-6.

18. Guo WX, Sun JX, Cheng YQ, Shi J, Li N, Xue J, et al. Percutaneous radiofrequency ablation versus partial hepatectomy for small centrally located hepatocellular carcinoma. World J Surg. 2013;37(3):602-7.

19. Jiang L, Yan L, Wen T, Li B, Zeng Y, Yang J, et al. Comparison of Outcomes of Hepatic Resection and Radiofrequency Ablation for Hepatocellular Carcinoma Patients with Multifocal Tumors Meeting the Barcelona-Clinic Liver Cancer Stage A Classification. J Am Coll Surg. 2015;221(5):951-61.

20. Zhaoyou T, Yeqin Y, Zhiying L, Xinda Z, Binghui Y, Yunzhen C, et al. Small hepatocellular carcinoma: clinical analysis of 30 cases. Chin Med J (Engl). 1979;92(7):455-62.

21. Bismuth H, Chiche L, Adam R, Castaing D, Diamond T, Dennison A. Liver resection versus transplantation for hepatocellular carcinoma in cirrhotic patients. Ann Surg. 1993;218(2):145-51.

Cite this article as: Adhikari R, Wen T, Shrestha P, Adhikari P. Comparison of the outcome of radiofrequency ablation or hepatic resection between solitary hepatocellular carcinoma and oligonodular hepatocellular carcinoma meeting Milan criteria: a systematic review and meta-analysis. Int Surg J 2019;6:3449-59. 